\title{
Maternal-fetal unit interactions and eutherian neocortical development and evolution
}

\author{
Juan F. Montiel ${ }^{1}$ *, Heidy Kaune ${ }^{1,2}$ and Manuel Maliqueo ${ }^{3}$ \\ ${ }_{1}^{1}$ Centre for Biomedical Research, Facultad de Medicina, Universidad Diego Portales, Santiago, Chile. \\ ${ }^{2}$ Nuffield Department of Obstetrics and Gynaecology, University of Oxford, Oxford, UK. \\ ${ }^{3}$ Laboratorio de Endocrinología y Metabolismo, Departamento de Medicina Occidente, Facultad de Medicina, Universidad de Chile, Santiago, Chile.
}

\section{Edited by:}

Eric Lewitus, Max Planck Institute for Molecular Cell Biology and Genetics, Germany

\section{Reviewed by:}

Alino Martinez-Marcos, Universidad de Castilla, Spain

Anna Hoerder-Suabedissen,

University of Oxford, UK

Alexandre Bonnin, University of

Southern California, USA

\section{*Correspondence:}

Juan F. Montiel, Center for Biomedical Research, Facultad de Medicina, Universidad Diego Portales, Av. Ejército 141, Santiago 8370068, Chile e-mail: juan.montiel@udp.cl
The conserved brain design that primates inherited from early mammals differs from the variable adult brain size and species-specific brain dominances observed across mammals. This variability relies on the emergence of specialized cerebral cortical regions and subcompartments, triggering an increase in brain size, areal interconnectivity and histological complexity that ultimately lies on the activation of developmental programs. Structural placental features are not well correlated with brain enlargement; however, several endocrine pathways could be tuned with the activation of neuronal progenitors in the proliferative neocortical compartments. In this article, we reviewed some mechanisms of eutherians maternal-fetal unit interactions associated with brain development and evolution. We propose a hypothesis of brain evolution where proliferative compartments in primates become activated by "non-classical" endocrine placental signals participating in different steps of corticogenesis. Changes in the inner placental structure, along with placenta endocrine stimuli over the cortical proliferative activity would allow mammalian brain enlargement with a concomitant shorter gestation span, as an evolutionary strategy to escape from parent-offspring conflict.

Keywords: cerebral cortex development, placenta, maternal-fetal unit, evolution, serotonin, eutherians, transcriptome

\section{INTRODUCTION}

Placenta and brain are not recent innovations in vertebrate phylogeny (Aboitiz and Montiel, 2007; Renfree et al., 2013). Placental species emerge in a wide variety of taxa, even among invertebrates and basal vertebrates, involving multiple cases of analogous convergence (Blackburn, 1992; Renfree et al., 2013). In turn, brain origin can be tracked before the emergence of vertebrates (Aboitiz and Montiel, 2007). Both structures exhibit an important level of anatomical diversification across vertebrates and inside mammalian evolution. Placenta structural diversification is associated with life-history, and functional, genomics, and environmental requirements (Lewitus and Soligo, 2011), whereas brain shape variability is related to different functional dominances, behavioral repertories, and cognitive capacities (Krubitzer, 2007). The acquisition of a large brain size in mammalian evolution (Rowe et al., 2011) is mainly explained by the activation of developmental programs that allow a radial and tangential laminar expansion of the cerebral cortical surface (Cheung et al., 2007, 2010; Aboitiz and Montiel, 2012; Molnár and Clowry, 2012). These events are correlated with the activation, and functional specialization of cortical proliferative compartments, named ventricular zone (VZ) and subventricular zone (SVZ; Kriegstein et al., 2006; Molnár etal., 2006; Cheung etal., 2007, 2010; Molnár, 2011; Aboitiz and Montiel, 2012). These proliferative compartments are susceptible to be regulated by locally, nearby, and distantly originated signals. In this regard, brain development is dependent on (1) local cues and in situ cell-autonomousspecification (Franco et al., 2012), (2) neighboring information from telencephalic-signaling centers and developing connections (Dehay et al., 2001; Shimogori et al., 2004; Medina and Abellán, 2009; Aboitiz, 2011; Aboitiz and Montiel, 2012), and (3) distant systemic interactions that coordinate intrauterine and environmental regulations with brain development. This kind of control has been less explored in evolutionary neurobiology since most hypotheses about brain origin and evolution are focused on the intrinsic developmental control (local and neighboring signals) and functional properties of the brain (Karten, 1969, 1997; Aboitiz et al., 2003; Aboitiz and Montiel, 2007). During brain development, some of these distantly generated molecules participate in proliferative induction, myelination, cell differentiation, migration, growing of neuronal projections, and signaling (Vitalis and Parnavelas, 2003). In addition, they provide information to the fetus about environmental and maternal conditions through the placenta. In this review, we describe some maternal-fetal interactions and their plausible associations with brain evolution and development. In an attempt to integrate evolutionary, developmental, and genomic data, we discuss (1) the evolutionary origin of mammals, (2) the comparative morphology of placenta, (3) neocortical development, (4) placenta-brain endocrine interactions, (5) potential molecular placenta-brain interactions extracted from transcriptome databases, and (6) finally we speculate about a hypothesis for the neocortical expansion observed in mammalian evolution that integrates in situ and neighboring cues with the control based on endocrine signals from placenta, from which some represent new pathways that should be explored further. 


\section{EVOLUTIONARY ORIGIN OF MAMMALS}

The mammalian lineage arises from synapsids, a mammal-like reptile ancestor, diverged from other tetrapods about 300 million years ago (Mya) in the Carboniferous (geological period extended from $\sim 359$ to $\sim 299$ Mya; Gauthier et al., 1988). The early mammal-like reptile Probainognathus had slender and elongated cerebral hemispheres bearing a small dorsal slope that is believed to be a forerunner of the neocortex (Quiroga, 1980; Aboitiz et al., 2003; Aboitiz and Montiel, 2007). Synapsids gave rise to pelycosaurs, lizard-like animals succeeded in the late Permian (extended from $\sim 299$ to $252 \mathrm{Mya}$ ) by the therapsids (Kemp, 2006). Most therapsids became extinct by the end of the Triassic period (extended from $\sim 252$ to $\sim 201 \mathrm{Mya}$ ), but one group of carnivorous therapsids, called cynodonts, survived well into the Jurassic period (extended from $\sim 201$ to $\sim 145$ Mya; Carroll, 1988). Early cynodonts had a restricted sensory repertory and a poor sensory-motor integration with a relatively low encephalization quotient (EQ; a measure of relative brain size as a function of the total body size; Rowe et al., 2011). From cynodonts arose the eucynodonts or mammaliaforms, this group includes Jurassic fossils such as Sinoconodon and Morganucodon, whose gross morphology resembled that of some present-day insectivores (currently known as order Eulipotyphla; Rowe, 1996; Kaas, 2013). Eucynodonts differ from their predecessors by having an increased olfactory sensitivity, improved tactile resolution, and motor coordination (Rowe et al., 2011), which are functional changes that would contribute primarily to a first pulse of pre-mammalian encephalization (Rowe et al., 2011). This hemispheric expansion differentiates mammaliaforms from mammal-like reptiles and most other vertebrates (Rowe et al., 2011). Considering this evidence, it has been proposed that the brain expansion was a late event in the lineage leading to mammals, more or less coincident with the acquisition of modern mammalian characters observed in fossils like the basal mammaliaform, Morganucodon, or in the closest known extinct to mammals, Hadrocodium (KielanJaworowska et al., 2004; Aboitiz and Montiel, 2007; Rowe et al., 2011). Mammalia arose from eucynodonts in/or before the Early Jurassic ( 200 Mya; Kielan-Jaworowska et al., 2004). These ancestral mammals were characterized by an expansion of the olfactory sensory system, which has been linked to a genomic amplification of the olfactory receptors (Niimura, 2009; Rowe et al., 2011). In some descendant clades, the olfactory system was further elaborated, whereas in others it was reduced and replaced by other sensory modalities (Aboitiz et al., 2003; Aboitiz and Montiel, 2007; Krubitzer, 2007; Rowe et al., 2011). Only much later, acute visual and auditory systems evolved among mammals (Luo et al., 2011; Aboitiz and Montiel, 2012).

Three mammalian subclasses became extinct in different evolutionary moments. Triconodonta, the earliest lineage diverged in mammalian phylogeny, disappeared at the end of the Cretaceous period (extended from $\sim 145$ to $\sim 66$ Mya) leading to a lack of basal-related in living mammals. The second was the Multituberculata, and the latest extinguished was the infraclass of Theria called Palaeoryctoides. A recent analysis suggests that the first modern placental orders (eutherians) emerged around 2-3 million years later than the Cretaceous-Paleogene (K-Pg) extinction event occurred 66 Mya (O'Leary et al., 2013). It was predicted that these ancestors had a hemochorial placenta with trophoblast, gyrencephalic cerebral cortex and relatively high EQ (over 0.25 ) when compared with other vertebrates (O'Leary et al., 2013). Phylogenetic analyzes of the living eutherian mammals identify four primary superordinal clades: Afrotheria, Xenarthra, Euarchontoglires, and Laurasiatheria (for a list of species belonging each group please see Table 1). The basal diversification

Table 1 | Primary clades of eutherian living mammals.

\section{Class Supercohort Infraclass Superorder ORDER and/or Suborder; animal examples/}

Mammalia Theria Eutheria Afrotheria

Xenarthra

Euarchontoglires

Laurasiatheria

Metatheria
AFROSORICIDA: Chrysochloridea; golden mole/ Tenrecidae; tenrecs/ MACROSCELIDEA; elephant shrews (sengis)/ TUBULIDENTATA; aardvarks/ HYRACOIDEA (hyraxes); rock hyrax/ PROBOSCIDEA; elephants/ SIRENIA; sea cows (dunging and manatees)

Vermilingua; anteaters/ Folivora; tree sloths/ CINGULATA; armadillos

RODENTIA; rat, mouse, capybara/ LAGOMORPHA; rabbits and hares, treeshrews/ DERMOPTERA; colugos/ PRIMATES; prosimians and simians

EULIPOTYPHLA; shrews, hedgehogs/ PHOLIDOTA, pangolins/ CHIROPTERA; bats/ CETACEA; whales/ ARTIODACTYLA; most hoofed mammals (such as hippopotamuses)/ CARNIVORA; cats, dogs, bears, seals, etc

DIPROTODONTIA; kangaroo, koala, possum, wombat/ DASYUROMORPHIA; tasmanian devil, quolls, dunnarts, numbat/ MICROBIOTHERIA; monito del monte/ PERAMELEMORPHIA; bilbies and bandicoots/ NOTORYCTEMORPHIA; Marsupial moles/ DIDELPHIMORPHIA; opossums/ PAUCITUBERCULATA; shrew opossums. 
A

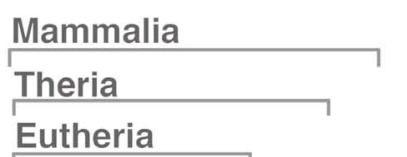

B

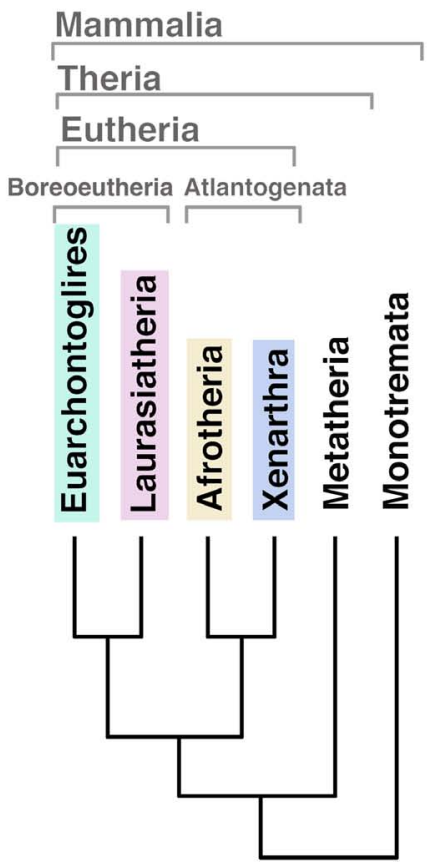

C

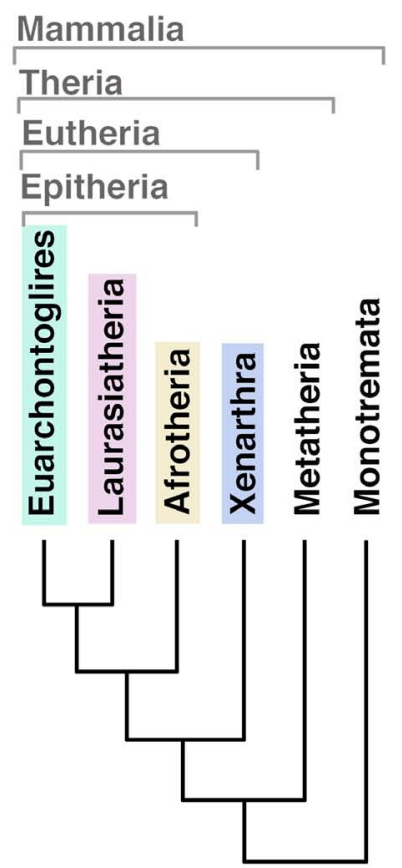

FIGURE 1 | Different outputs for the basal relationships among eutherian mammal superordinal clades. (A) Afrotheria as the most basal mammalian clade, sister lineage of exafroplacentalia (all other eutherians, also called notolegia). (B) Atlantogenata (Afrotheria and Xenarthra) as sister lineage of Boreoeutheria (Euarchontoglires and Laurasiatheria). (C) Xenarthra as the most basal clade, sister lineage of Epitheria (all other eutherians). of eutherians has been historically considered an unstable node (O'Leary et al., 2013) and the phylogenetic relationship between these lineages is still under debate since different analyzes have generated different outputs of ancestry (Figure 1). Using 18 homologous genes segments, Afrotheria was originally positioned as the most basal mammalian clade, with Xenarthra as the second, and Euarchontoglires and Laurasiatheria as the third branches of the mammalian tree (Murphy et al., 2001; Figure 1A). Using genomic sequences, the phylogenetic relationship of mammals has been re-informed (Murphy et al., 2007) and "confirmed" (Prasad et al., 2008), positioning Atlantogenata (Afrotheria and Xenarthra) together as sister lineages of Boreoeutheria (Euarchontoglires and Laurasiatheria; Figure 1B). A recent publication renewed this debate resolving this basal relation as a split between Xenarthra and Epitheria (Afrotheria, Laurasiatheria and Euarchontoglires; O'Leary et al., 2013; Figure 1C).

\section{COMPARATIVE MORPHOLOGY OF PLACENTA}

Understanding the organization of the phylogenetic tree of mammals allows the visualization of the evolutionary history of different traits and the definition of the presumed ancestral structure of the placenta (Wildman et al., 2006). The acquisition of the placenta implies as first requirement, the emergence of viviparity (live-bearing) since this made possible the elaboration of specialized structures that allowed the development of the eggs within the maternal body, providing nutrition and protection. It has been postulated that placenta has evolved concomitantly with the viviparity more than 100 times in different lineages of non-mammal amniotes (Crespi and Semeniuk, 2004). The most ancient evidence of viviparity in amniotes arise from fossils of mosasauroids, a cretaceous marine lizard, containing embryos along the posterior trunk region (Caldwell and Lee, 2001). The reptile ancestor of mammalian lineage was oviparous (egg-laying) since in reptiles viviparity has evolved more recently than in mammals (Blackburn, 1992). The mammalian common ancestor of monotremes (which lay eggs) and therians was presumably egg-laying as well (Oftedal, 2002). Supporting evidence for this is that in reptiles oviparity can evolve into viviparity via a sequential increase in the duration of egg-retention, as it has been seen in lizards and snakes (Blackburn, 1992). Once committed to viviparity, the eggshell membrane thickness is drastically reduced, thus, return to oviparity from viviparity has not been seen in amniotes (Oftedal, 2002).

The diversity of placental structures found among species is remarkable. Differences in placental shape, degree of the relationship between the chorion and uterine wall, number of layers of trophoblast, shape of maternal-fetal interdigitation (villous, trabecular or labyrinthine), variations in the interhemal barrier mainly characterized by different degrees of hypertrophy of maternal endothelium and presence of cytotrophoblast and/or syncytial trophoblast are commonly observed (Enders and Blankenship, 1999; Enders and Carter, 2004). Three main types of placentas can be recognized according to the extent of how the fetal tissue invades the wall of the uterus or the maternal vessels. In general, epitheliochorial placenta is an extensive and diffuse structure, 

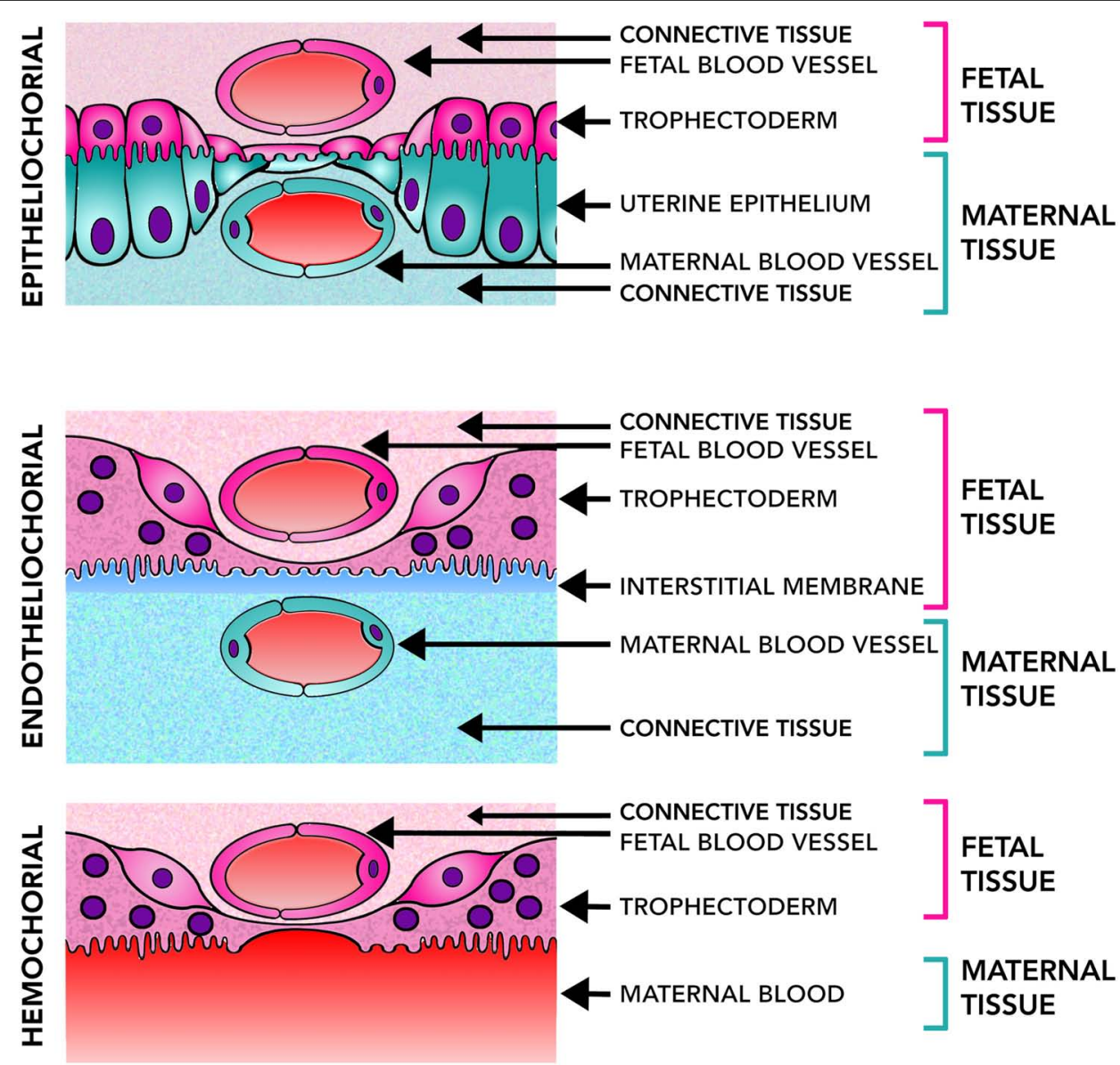

FIGURE 2 | Placental level of invasiveness. The placenta varies across mammalian species in the invasiveness and their access to maternal blood flow. Epitheliochorial placentas, the least invasive, have three layers of maternal tissue separating the fetus from maternal blood. Endotheliochorial placentas are partially invasive and only the endothelial wall of the maternal blood vessels, and some interstitial tissue, separates the fetus from the maternal blood. Hemochorial placentation is the most invasive and allows fetal tissues to be bathed directly in the maternal blood. Epitheliochorial and Endotheliochorial placentas can be found in Afrotheria, Euarchontoglires and more frequently in Laurasiatheria. Hemochorial placentas are found in all eutherian superorders (Wildman etal., 2006), showing a broad distribution of placental types in the mammalian class. lining the uterine wall, and exhibiting limited invasiveness without trophoblast invasion of uterine vessels. In the endotheliochorial placenta, a network of maternal capillary grows within the trophoblast, allowing a better exchange between the mother and fetus and reducing the risk of passing fetal cells into the maternal circulatory system. Finally, in the hemochorial placenta, the maternal blood is in direct contact with the trophoblast, which has the advantage of a more efficient nutrient uptake and waste elimination (Figure 2). This extensive maternal-fetal communication also implies some disadvantages like a major risk of maternal bleeding after delivery and a greater chance of fetal cells transfer to the maternal system (Enders and Carter, 2004).

\section{MORPHOLOGICAL PLACENTAL ORGANIZATION ACROSS LIVING MAMMALIAN SPECIES IS ASSOCIATED WITH SHORTER GESTATIONS AND MATERNAL INVESTMENT SPAN REDUCTION}

The eutherian lineage displays a huge placentation diversification. Mess and Carter (2006) developed an exhaustive analysis of 19 morphological features and degrees of development at birth across 35 mammalian species, getting a plausible placental profile of the stem ancestor of living mammals (Carter and Mess, 2007; Capellini, 2012). The authors used a cladistics analysis placing Afrotheria and Xenarthra as sister to other eutherians, which agrees with the phylogeny of living mammals obtained from genomic data (Murphy etal., 2007; Prasad etal., 2008). Together with recent studies focused on defining the ancestral structure of the eutherian placenta, these studies agreed that this ancestral placenta had a hemochorial interface, discoid shape, and labyrinthine maternal-fetal interdigitations (Wildman et al., 2006; Capellini, 2012). Although the placenta organization is highly variable between mammals, the ancestral hemochorial and discoid placenta structure has been preserved in haplorhine (tarsiers, new and old word monkeys, and apes) primates (Vogel, 2005; Wildman et al., 2006; Lewitus and Soligo, 2011). As these big-brained mammals conserve the ancestral placental organization and share this feature with small-brained mammals it is questionable that structural differences in placenta can account 
for brain size expansion across mammalian evolution. However, different structural placental features have been associated with brain enlargement, leading to conflictive conclusions. One of these relies on the brain as a highly expensive organ to grow and maintain (Elliot and Crespi, 2008), so it was proposed that a highly invasive hemochorial placentation (Figure 2) is necessary for fetal brain growth. However, this relation is not supported once the analyzes are refined (Sacher and Staffeldt, 1974; Capellini et al., 2011). Even more, dolphins, as humans, have a relative larger brain; nevertheless, they possess an epitheliochorial placenta (Figure 2). Accordingly, invasiveness of the placenta is not a requirement to develop large brains (Martin, 2003).

Bias in the inclusion of relatively small-brained marsupials against the largest-brained placental mammals (Laurasiatheria and especially Euarchontoglires), or the addition of preimplantation stages lacking placenta formation would hamper these comparisons between marsupial and eutherian mammals (Weisbecker and Goswami, 2010; Capellini etal., 2011). Recently, Capellini (2012) analyzed different placental attributes, concluding that whereas invasiveness association to fetal and brain growing is not supported by comparative studies, species with highly interdigitated labyrinthine placentas produce neonates of similar body and brain size but in less than half the gestational time than those associated with less interdigitated (villous and trabecular) placentas. Capellini suggested that the effects of placental interdigitation on growth rates and the way that these are traded off against gestation length may be important for understanding the evolutionary dynamics of parent-offspring conflict.

\section{NEOCORTICAL DEVELOPMENT}

Most neurons in the neocortex derive from multipotent neural stem cells in the proliferative epithelium of the VZ lining the ventricular surface of the telencephalic wall. In the VZ, radial glial cells will generate lower- and upper-layer neurons according to distinct fate potentials (Franco et al., 2012), the Cux2 negative radial glia first produces excitatory neurons, most of which migrate radially to make up the embryonic preplate and the deepest cortical layers, instead Cux2 positive radial glia are fated to generate upper-layer neurons (Franco et al., 2012). Later in development, divisions of the Cux2 positive radial glia produce cells called intermediate progenitors, that detach from the ventricular surface and aggregate in a zone overlying the VZ (Kriegstein et al., 2006; Franco et al., 2012), the SVZ, a second proliferative compartment that is under control of Pax6 transcriptional factor and express Svet1, Cux2, and Tbr 2 genes. In the SVZ, cells undergo one to three more cell divisions and then migrate to build up the superficial layers of the neocortex. Neurons generated in successively later moments are incorporated into progressively more superficial layers, generating the inside-out neurogenetic gradient that is characteristic of the neocortex.

\section{THE ACTIVATION OF PROLIFERATIVE COMPARTMENTS AS A STRATEGY FOR NEOCORTICAL EXPANSION}

According to recent models of neocortical growth, early tangential expansion of the neocortex is based primarily on the divisions of primary progenitors, which enlarge the surface of the VZ, and later on the tangential growth and radial thickening (generation of superficial layers) of the neocortex depending mainly on the proliferation of cortical intermediate progenitors (Dehay and Kennedy, 2007; Pontious et al., 2008) and glial-like neurons located in the SVZ (Reillo et al., 2011; Wang et al., 2011b; Molnár et al., 2011). From a comparative perspective, there seem to be an increased cell number in mammals in an arbitrary unit column of cortex (Cheung et al., 2007, 2010). Adult mice or macaques possess a significantly higher number of cerebral cortical neurons compared with marsupials (Cheung et al., 2007, 2010). The presence of intermediate (or basal) progenitor cell divisions and gene expression patterns suggest that the SVZ emerged prior to the Eutherian-Metatherian split and it might have been the major driving force behind the evolution of the six-layered neocortex in mammals (Cheung et al., 2007, 2010; Aboitiz, 2011; Aboitiz and Montiel, 2012; Molnár and Clowry, 2012). Interestingly, while a VZ has been described in all vertebrates that have been studied, a distinctive dorsal pallial SVZ appears only in some species. Among mammals, the SVZ extends from the lateroventral aspect of the hemisphere to the dorsal pallium. Across species, the growth of the SVZ appears to correlate with the development of the superficial neocortical layers, being especially complex in primates and minimal in marsupials (Cheung et al., 2010; Molnár, 2011). Underlying the neurogenetic development, there is a molecular regionalization process in which the cortical neuroepithelium acquires its identity on the basis of the expression of regulatory genes that control the pattern of differentiation, yielding its characteristic adult phenotype. Molecular evidence indicates that the embryonic cerebral hemispheres are patterned according to several signaling centers from which morphogens are produced and expressed in gradients in different directions (Sur and Rubenstein, 2005; O'Leary and Sahara, 2008; Medina and Abellán, 2009). Thus, modulation of such gradients may yield to important changes in brain development, expanding some regions and reducing others (Medina and Abellán, 2009; Aboitiz, 2011; Aboitiz and Montiel, 2012; Figure 3). We believe that several traits of cortical neurodevelopment would account for the high mean EQ of Euarchontoglires and especially of large-brained primates (Aboitiz and Montiel, 2012; Molnár and Clowry, 2012). Primates developed a subcompartmentalized neocortical proliferative SVZ (García-Moreno et al., 2012), and an extra-laminated transient subplate (Wang et al., 2010, 2011a; Montiel et al., 2011). Together with other changes, these characteristics allowed a radial and tangential cortical expansion and consequently allowed to alter the conserved brain design that primates inherited from early mammals (Aboitiz and Montiel, 2012).

\section{PLACENTA-BRAIN ENDOCRINE INTERACTIONS}

In some way, placenta resembles the function of several endocrine systems; thus it is positioned as the main endocrine organ throughout intrauterine development. Placenta produces and releases a number of signaling substances including cytokines, neuropeptides, neurosteroids, and amines (Petraglia et al., 1996). Some of them are known for influencing fetal brain development, e.g., regulating the synthesis of neuroactive factors and corticogenesis (Petraglia et al., 2010). Placenta is a crucial regulator of maternalfetal interactions (Hsiao and Patterson, 2012). Indeed, structural 


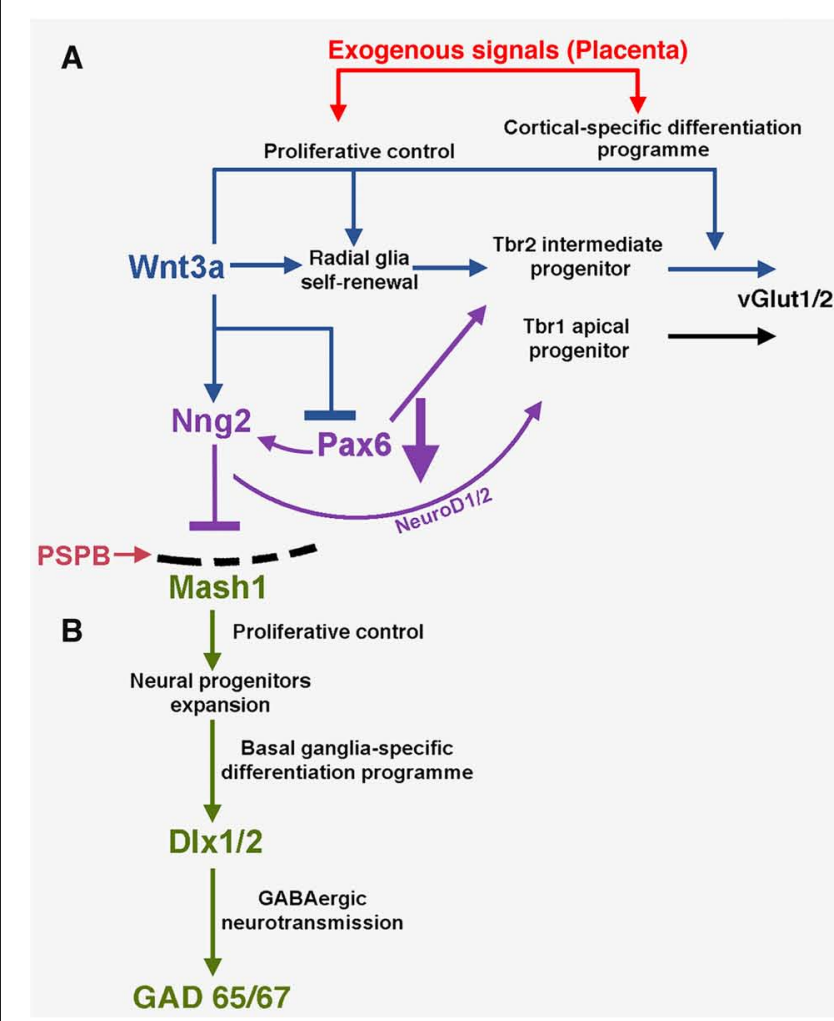

FIGURE 3 | Exogenous signals from placenta would complement telencephalic-signaling control during brain development. (A) The upregulation of Wnt3a trough the canonical Wnt pathway induce self-renewal of radial glia, early differentiation of Tbr2 cortical intermediate progenitors (Munji etal., 2011) and restrict the expansion of the ventral pallium (antihem) driven by Pax6. The antihem express secreted Frizzled-Related Proteins (Sfpr1 and 2, not shown) that neutralize the action of dorsally derived signals like Wnts. Pax6 activates the expression of the dorsal proneural factor neurogenin $1 / 2$ with the consequent activation of NeuroD1/2 and inhibition of Mash1, a proneural factor highly expressed in subpallial domains. Thus, the pallial/subpallial boundary is defined by the limit of expression of Ngn2 and
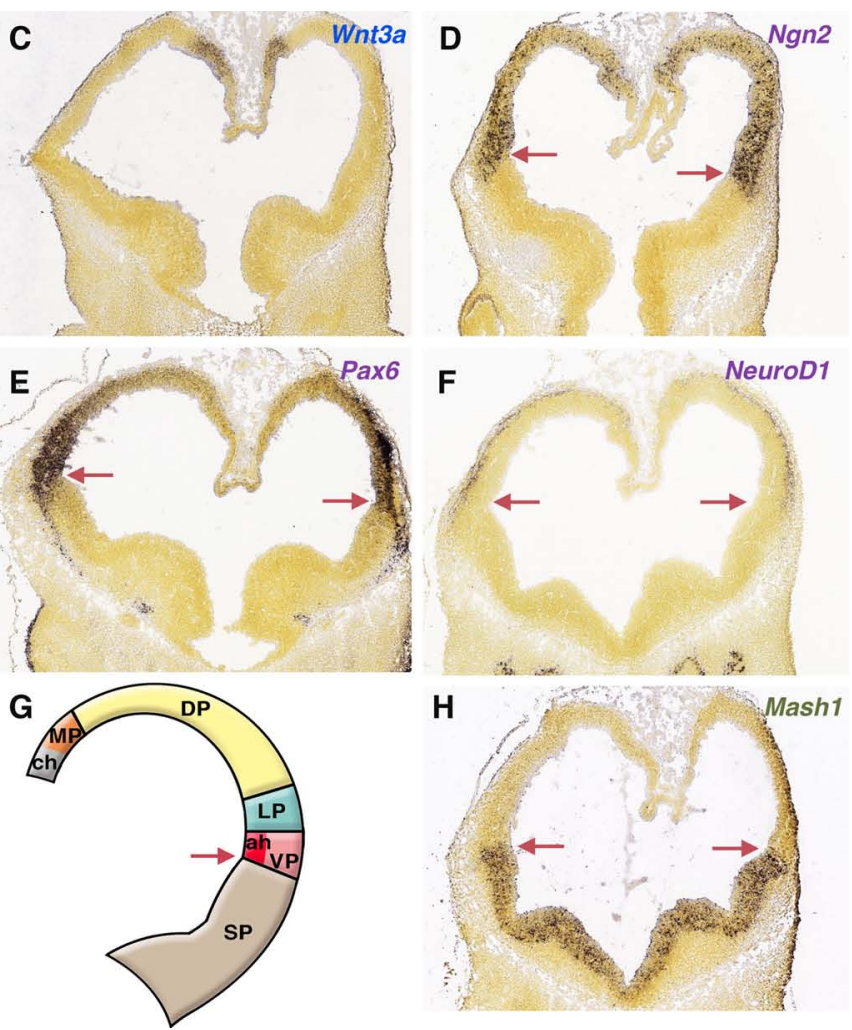

Mash1 (red arrow in A, D-H). (B) Mash1 induces a first group of transcripts in the phase of expansion of neural progenitors (Castro et al., 2011) and activates a second group of genes at the subsequent phases of cell cycle exit and neuronal differentiation (Bertrand et al., 2002). (C-F) In situ hybridization (ISH) expression pattern of signaling factors in mouse at developmental stage E11.5 (G) Gene expression of signals/factors that helps to define the telencephalic compartmentalization. (H) Subpallial expression of Mash1 at E11.5. All ISH images were taken from the Allen Developing Mouse Brain Atlas, available from: http://developingmouse.brain-map.org. ch, cortical hem; LP, lateral pallium; MP, medial pallium; VP, ventral pallium; SP, subpallium. changes in placenta are associated with the development of diseases in later life (Barker et al., 1990). Moreover, placenta's roles in regulating nutrient transport, endocrine function and immune tolerance are involved in growth restriction, hypoxia, and neurological complications (Fernandez-Twinn et al., 2003; Jansson and Powell, 2007). Several functional pathways associate this organ with brain development and, recently, reciprocal interactions from the brain to placenta have been proposed (Ugrumov, 2010). In addition, the tightening of the blood-brain barrier is a gradual process, with an earliest angiogenesis phase occurring during early brain developmental stages (E13-E14 in rat). This is characterized by a high paracellular permeability (Liebner et al., 2011) and therefore permitting fluent molecular interactions, which potentially allows the placenta to participate in brain development (Bonnin et al., 2011).

\section{SEROTONIN AND NEUROGENIC CONTROL}

One of these maternal-fetal interactions is through serotonin (5-HT) pathway. This neuroactive factor has been associated with proliferative activity, migration, and differentiation processes during neocortical development (Vitalis and Parnavelas, 2003). Originally, it was though that endogenous sources of 5HT were responsible for the stimulation of corticogenesis, but since there is a mismatch between this endogenous generation of 5-HT (serotoninergic axons reach the corticostriatal junction at E16 in rats) and the peak of cortical neurogenesis (E12-E17; Vitalis and Parnavelas, 2003), placenta/brain interaction could not be explained by endogenous sources of 5-HT (Figure 4). Instead, the exogenous source of 5-HT produced by the placenta is required to maintain normal levels of forebrain 5-HT during early stages of brain development (Bonnin et al., 2011) and would explain the developmental-functional association between $5-\mathrm{HT}$ and cortical development. Receptiveness to 5-HT during early stages of cerebral cortical development depends on the expression of 5-HT receptor subtypes in the developing cortex (Lidow and Rakic, 1995; Vitalis and Parnavelas, 2003). For an accurate expression mapping of 5-HT1 receptors in mouse see Bonnin et al. (2006). Interestingly, in monkeys, high levels of 5-HT receptors 


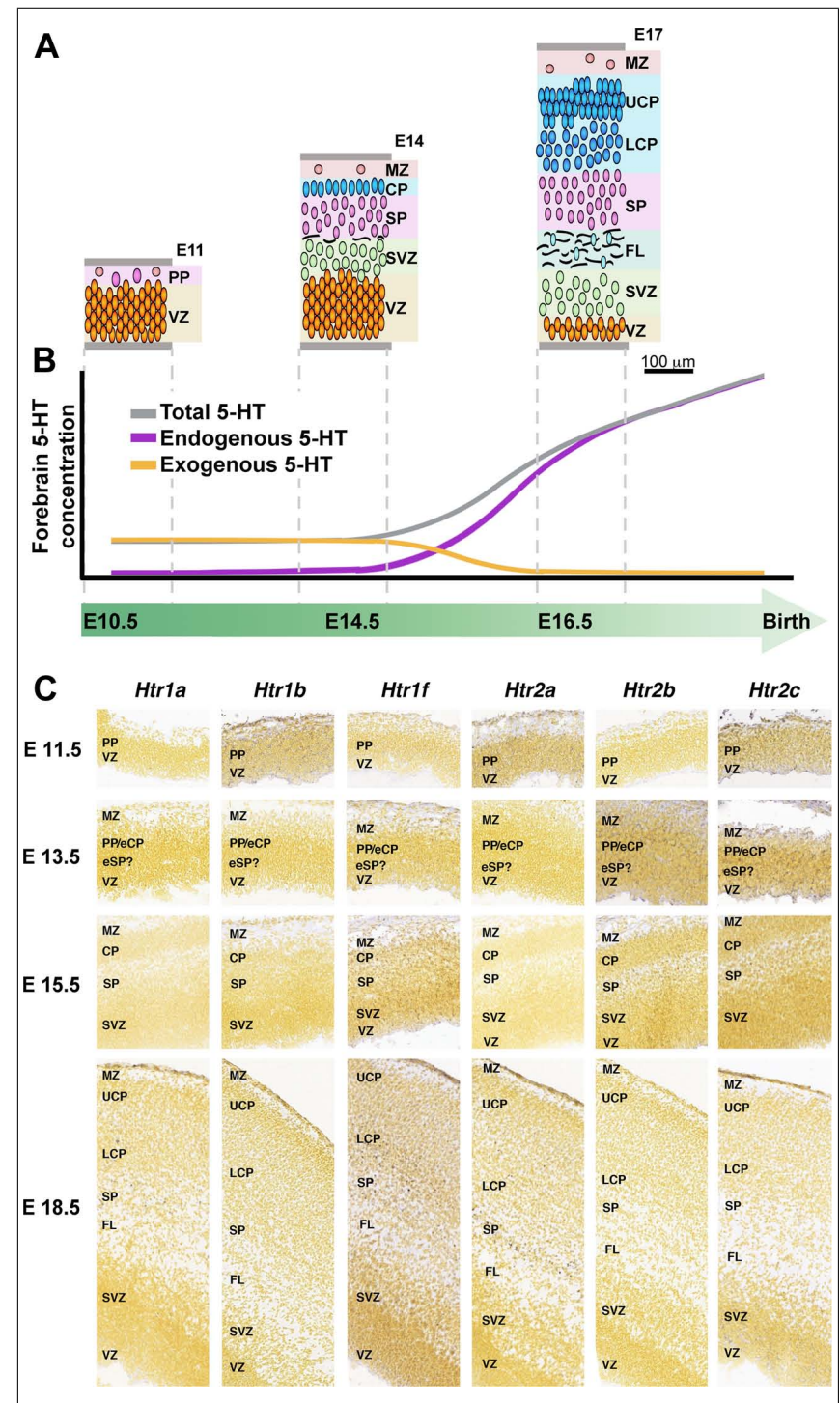

FIGURE 4 | 5-HT and 5-HT receptors in mouse developing cerebral cortex. (A) Organization of the developing mouse cortex at E11, E14, and E17, modified from Smart et al. (2002) with permission. (B) Dynamic of 5-HT brain sources during intrauterine development, early exogenous (placenta; orange line) switch to a latter endogenous (5-HT brainstem axons, purple line) 5-HT source, modified from Bonnin et al. (2011), with permission. (C) Expression of 5-HT receptors during mouse cortical development, ISH obtained from Allen Developing Mouse Brain Atlas, available from: http://developingmouse.brain-map.org. CP, cortical plate; eCP, early cortical plate; eSP, early subplate; $F L$, fiber layer; LCP, lower cortical plate; MZ, marginal zone; PP, preplate; SP, subplate; SVZ, subventricular zone; VZ, ventricular zone; UCP, upper cortical plate.

expression have been reported in the proliferative zones of the occipital lobe during neurogenesis (Lidow and Rakic, 1995). Moreover, some 5-HT receptors have been shown to be functional before birth, suggesting that they may orchestrate early steps of cortical development. A postnatal injection of 5-HT1 receptors agonist increases the number of hippocampal precursors and neurons (Vitalis and Parnavelas, 2003), instead hippocampal proliferation of precursors is repressed when the 5-HT synthesis is pharmacologically inhibited (Brezun and Daszuta, 1999; Vitalis and Parnavelas, 2003). 5-HT stimulation also promotes differentiation, and therefore it is not clear whether 5-HT stimulation mediates proliferation or simply speeds up the cell cycle (Vitalis and Parnavelas, 2003). Interestingly, embryonic pharmacological depletion of 5-HT (Vitalis and Parnavelas, 2003) and cocaine administration (which interacts with the 5-HT pathways; Clarke et al., 1996), both induce microcephaly. Elevated 5-HT output associated with a reduced 5-HT transporter and 5-HT1A receptor have been observed in hippocampus of adult animals that underwent prenatal stress during fetal life, supporting the role of prenatal imprinting on behavioral alterations in adult life (Van den Hove et al., 2006; Mueller and Bale, 2008).

\section{PLACENTAL STEROIDS AND BRAIN DEVELOPMENT}

During pregnancy in mammals, placenta produces a large amount of steroids, which are crucial for the survival, development, and health of the developing embryo. Progesterone and estrogens (estrone, estradiol, estriol, and its conjugated forms) are the main hormones during pregnancy. Progesterone is fundamental to modulate the maternal immune response allowing the maternal tolerance of the fetal "semi-allograft." On the other hand, estrogens are needed to promote the placental growth and angiogenesis and influence fetal growth and metabolism. These steroids are in extremely high concentrations in maternal circulation. However, placental tissue can metabolize them to inactive forms in order to avoid fetal exposure. Many of these metabolites can act as neurosteroids in adult brain, however, their contribution to fetal brain development remains under debate. For example, allopregnanolone, a progesterone metabolite modulates the activity of GABAergic and glutamatergic neurons in fetal brain and may mitigate the brain injury provoked by asphyxia in the hippocampal region, since allopregnanolone can control the proliferation and apoptotic patterns in cerebellum and hippocampus (Nicol et al., 1999; Yawno et al., 2007, 2009).

Similar to sex steroids, glucocorticoids levels are lower in fetal than in maternal circulation. This difference is attributable to the high expression of $11 \beta$ hydroxysteroid dehydrogenase type $2(11 \beta$-HSD2) in both the placenta and fetus. In the placenta, $11 \beta$-HSD2 catalyzes the rapid inactivation of cortisol and corticosterone to inert 11 keto-products, and then it serves as a "glucocorticoid barrier," modulating the transfer of glucocorticoids to the fetus. In the placenta, $11 \beta$-HSD2 is highly expressed in the syncytiotrophoblast of humans and in the labyrinthine zone of rodents (Brown et al., 1996; Waddell et al., 2012). Interestingly, animal models of maternal stress have been associated with lower expression of placental $11 \beta$-HSD2 and low birth weight in rodents, suggesting a relationship with fetal programming (Fowden et al., 2008).

In general, normal concentrations of glucocorticoids are essential in the development of many organs, including central nervous system. However, some conditions associated with elevated levels of glucocorticoids, as stress or reduced capacity of placenta to metabolize it, can leads to detrimental effects on brain development and long-term behavioral effects, since glucocorticoid receptors are highly expressed in some brain areas like hippocampus (Reul and de Kloet, 1985). Primate models of stress and 
dexamethasone-exposure during pregnancy, exhibit degenerative changes and reduction of brain volume, associated with lower number of neurons in the hippocampus (Uno et al., 1989, 1990; Coe et al., 2003). Moreover, these effects are maintained at least until 2 years after birth, suggesting a possible long-term effect in learning process and memory (Uno etal., 1994). In cerebral cortex, studies conducted in rodents have demonstrated a reduction in dendritic arborization and synaptic loss in frontal cortex of males but no effects were observed in females indicating a gender-specific mechanism of action (Barros et al., 2006). In addition, cerebellum exhibits a reduction in the volume fraction of granule cells nuclei in the granular layer with less synaptic density (Ulupinar and Yucel, 2005). Some evidence points out that prenatal glucocorticoid exposure can impact on serotonergic and catecholamine pathways. Therefore, we can hypothesize that the mechanism associated with endocrine function in placenta can impact brain development, probably playing a central role on brain evolution. However, the information about comparative endocrine function in different species is still limited, making it difficult to interpolate these functions to the eutherian ancestor.

\section{EXPLORING POTENTIAL MOLECULAR PLACENTA-BRAIN INTERACTIONS FROM TRANSCRIPTOME DATABASES}

High-throughput analysis of active transcripts is a powerful tool to explore possible molecular interactions across organs and species. Brain and placenta share some remarkable transcriptional features as the expression of imprinted genes and the expression of transcriptional pathways of immune interactions. Transcriptomes from placenta (Hou et al., 2012; Figure 5A) and developing neocortical brain compartments (Ayoub et al., 2011) can be clearly differentiated between different mammalian species (Ayoub et al., 2011; Hou etal., 2012). Comparing placenta transcriptomes of representative species from three eutherian superorders: elephant (Afrotheria), cow (Laurasiatheria), mouse, and human (Euarchontoglires), Hou and collaborators found 2,963 genes commonly expressed and a variable number of active transcripts with species-specific expression (elephant, 904; cow, 436; mouse, 1,235; and human, 1,365; Hou et al., 2012; Figure 5A). At this point of our on-going studies, we become interested in the published list of human placental differentially expressed genes (Hou et al., 2012), this species-specific set of genes exhibit significant functional enrichment (the top five are reproduced from originals in Figure 5B). The top one gene module is enriched in signal molecules (this module was originally labeled as glycoproteins, but we renamed it after reproduce this analysis to represent its enrichment in signal genes, Figure 5B).

We compared these human placental signal-enriched transcripts, and those transcripts from human developing cortex (including the VZ, inner and outer SVZs, and cortical plate; Fietz et al., 2012) looking for systemic protein-protein and general functional interactions. To do this, we investigated known and predicted protein interactions based on genomics, coexpression, and literature data using STRING 9.05 (http://string-db.org), a network analysis database focused on protein interactions (Szklarczyk etal., 2011; Franceschini etal., 2013; Lv etal., 2013; Figure 6).

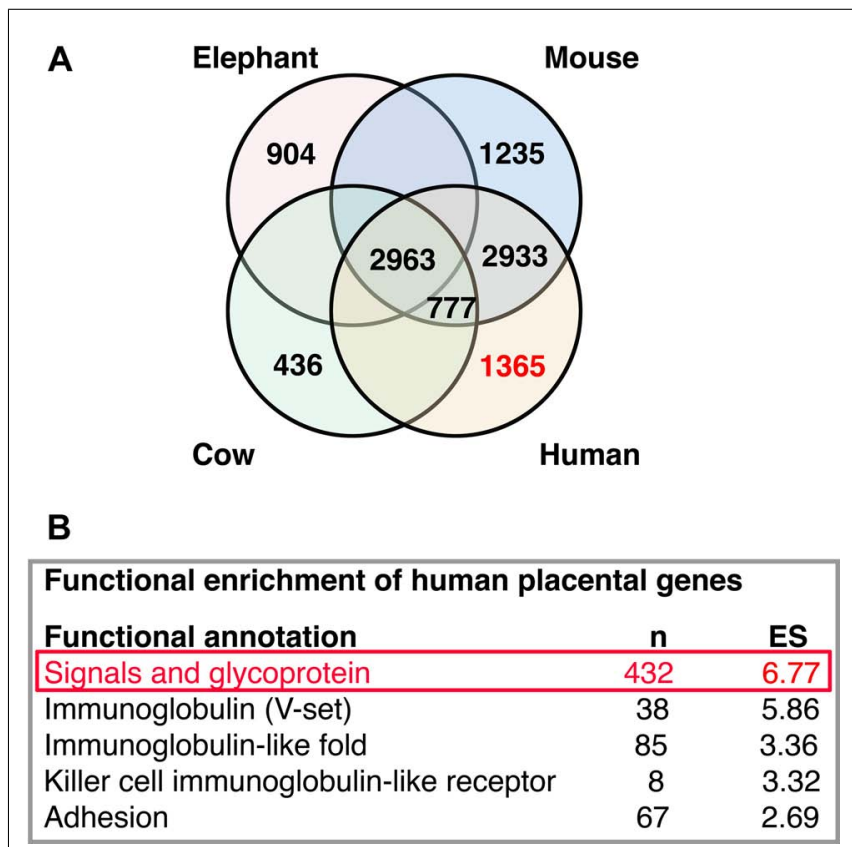

FIGURE 5 | Interactions analysis. (A) Distribution of placental transcripts obtained by Hou et al. (2012) and reproduced with permission. (B) Top five functional enrichments of human species-specific placental transcripts obtained by Hou et al. (2012) and reproduced with permission. The top one enriched module (in red) was further analyzed in Figure 6

We obtained 341 potential interactions from human placenta active transcripts, ranging a STRING's score from 0.404 to 0.998 , and initially not restricted to any target tissue. Then, we manually projected this list onto the developing human cortex transcriptome (Fietz et al., 2012) in order to detect plausible gene placenta-brain interactions, obtaining 112 interactions, involving 73 transcripts expressed only in the human placenta 20 transcripts coexpressed in the human placenta and the human developing cortex, and 24 transcripts expressed only in the human developing cortex. The genes expressed in the developing cortex and their placenta interacting counterparts have been represented as a gene network of protein interactions in the Figure 7.

\section{PLAUSIBLE PLACENTA-BRAIN INTERACTIONS PREDICTED BY TRANSCRIPTOMIC AND PATHWAY ANALYZES}

Some of the identified pathways have been associated directly or indirectly to proliferative activation, cell migration, and differentiation during cortical development, and related to several neurological disorders. CSPG5 (chondroitin sulfate proteoglycan 5) is expressed predominantly in the developing cortex participating in dendrite branching and synapses formation (Aono et al., 2000). CSPG5 interacts with the cell surface protein CD19 expressed in the placenta, with the CSPG4 proteoglycan (chondroitin sulfate proteoglycan 4) and with the transmembrane protein SDC4 (syndecan 4) placenta-brain coexpressed genes. Interestingly, transcriptomic analyzes have suggested that cell adhesion and cell-extracellular matrix interactions promote the proliferation and self-renewal of neural progenitors in the developing human neocortex (Fietz et al., 2012). LGALS1 (lectin, galactoside-binding, 


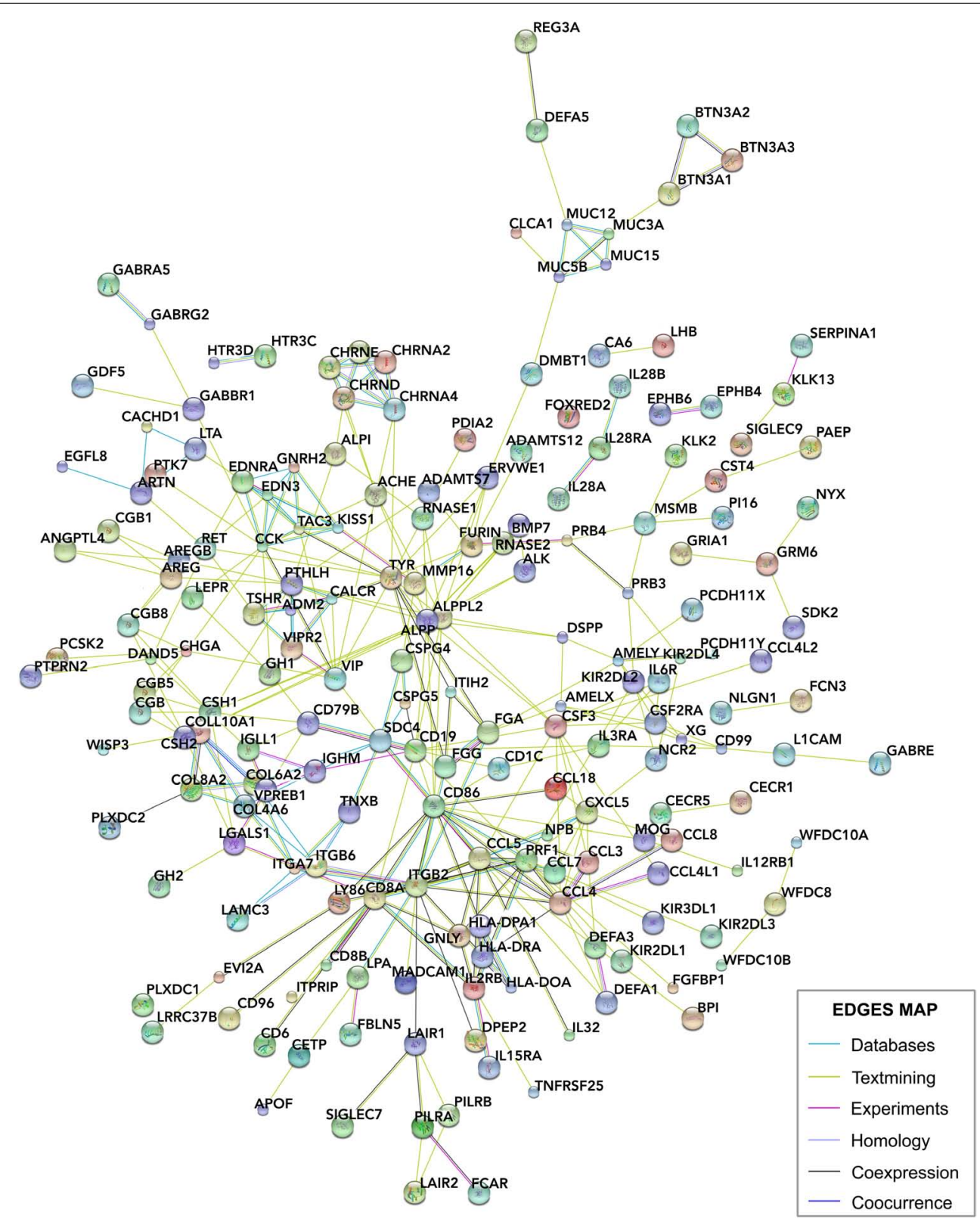

FIGURE 6 | STRING analysis of the interactions between placental genes. The signals and glycoprotein enriched module of human placental transcripts (Figure 5B) was analyzed using STRING 9.05 (http://string-db.org/), a database of known and predicted protein interactions, which responds by displaying a network of nodes (genes) connected by colored edges representing functional relationships. Interactions of these genes were identified based on the evidence indicated in the edges map. Unconnected genes were removed. soluble, 1), expressed in the developing cortex, encodes for galectin, a known regulator of neural stem cell proliferation (Sakaguchi et al., 2006; Imamura et al., 2008) and interacts with the cell surface glycoprotein CD8A placenta-brain coexpressed, and CSH1 (chorionic somatomammotropin hormone 1 or placental lactogen), $\mathrm{CSH} 2$ (chorionic somatomammotropin hormone 2), GH2 (growth hormone 2), and VPREB1 (pre-B lymphocyte 1; also named CD179A, cluster of differentiation 179A) placental genes. PTK7 (protein tyrosine kinase 7) expressed in the developing cortex, interacts with the peptide hormone CCK (cholecystokinin) from placenta and encodes a transmembrane receptor in the brain that controls a variety of developmental and physiological processes, including cell polarity, cell migration, invasion, and antagonize Wnt signaling (Peradziryi et al., 2011).

As mentioned above, placental 5-HT is an important regulator of fetal brain development. Our transcriptomic analysis suggests that other placental neuropeptides, as vasoactive intestinal peptide (VIP) and CCK could be related to the fetal brain development in humans. Moreover, according to comparative placental transcriptomic analysis (Hou et al., 2012), these neuropeptides are 


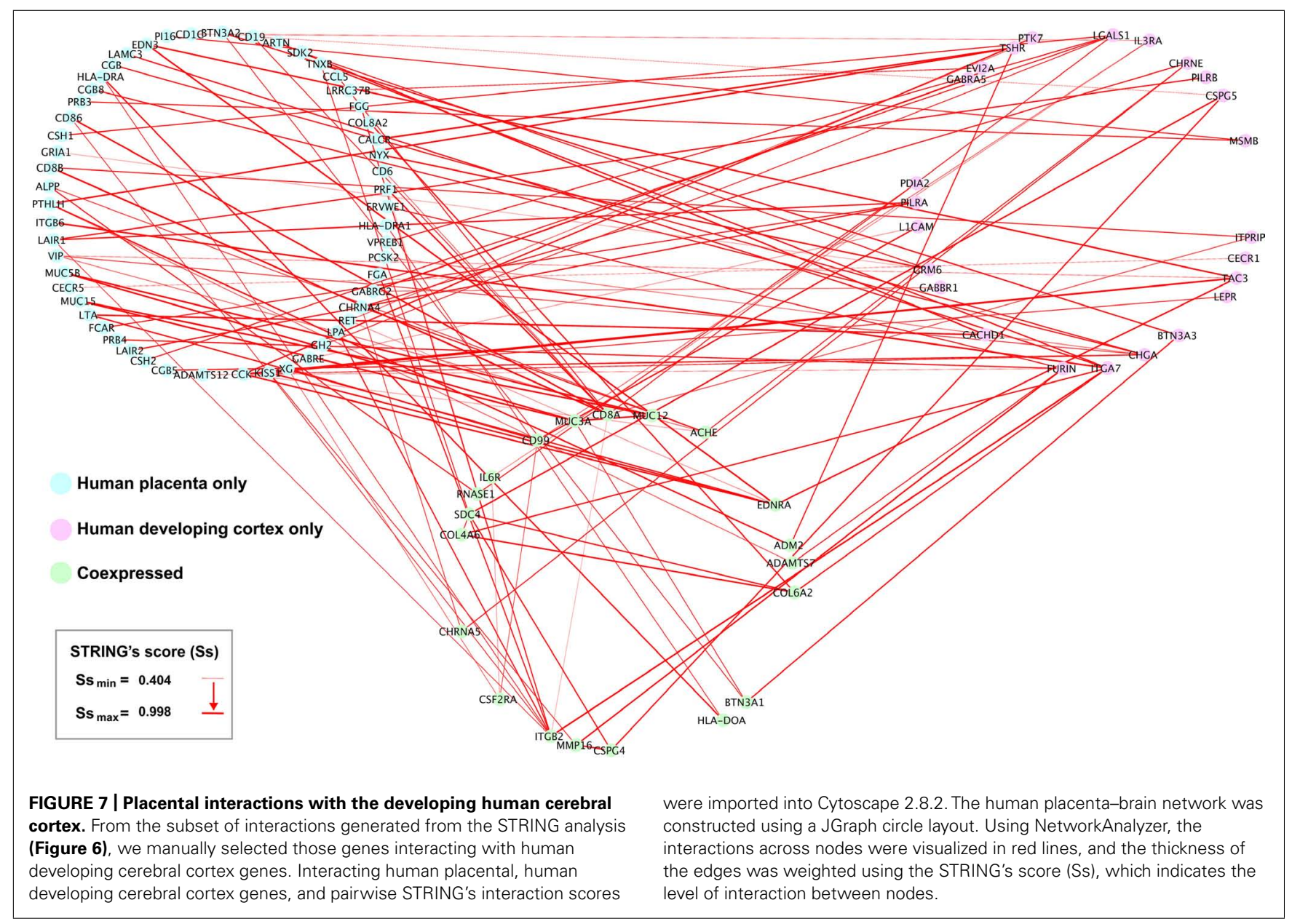

expressed in the human placenta but not in the mouse, cow or elephant placentas. Observations in mice showed that VIP has an influence over the brain and spinal cord development between E11 and E17. In the brain, VIP effects are specifically restricted to the cortex and tissue surrounding the ventricle. On the other hand, in the mouse the maternal levels of VIP are increased during E11, indicating a maternal VIP supply at early developmental stages from sources other than placenta (Hill et al., 1996; Hou et al., 2012). At difference, in humans has been found a placental source of VIP (Hou et al., 2012). Other studies have demonstrated that VIP can stimulate neurogenesis as well as differentiation and neurite outgrowth (Hill, 2007). Thus, maternal VIP from two different sources would be participating in the enlargement of the brain: a placental source observed in humans, and a non-placental source detected in mice.

Other gene interactions are elusive to be functionally interpreted, GABBR1 [gamma-aminobutyric acid (GABA) B receptor $1]$ is expressed in the developing cortex and interacts with other GABA receptor in the placenta (GABRG2, GABA A receptor, gamma 2). GABBR1 has been associated with anxiety (LeNiculescu et al., 2011), autism (Fatemi et al., 2009), schizophrenia (Hegyi, 2013), and epilepsy (Peters et al., 1998), but there are not reports about brain development implications. EDN (endothelin 3 ) is an endothelium-derived vasoactive peptide expressed in the placenta, involved in a variety of biological functions and interacting with EDNRA (endothelin receptor type A), which is expressed in the developing cortex and upregulated after hypoxic preconditioning in the immature brain (Gustavsson et al., 2007). On the other hand, CCK has been identified in different brain areas through development. In mouse embryos, CCK expression first appears at E8.5-E9.5 in the neural crest cells and their precursors (Lay et al., 1999). In the embryonic rat brain CCK is expressed in the ventral tegmental area and in the primordium of the medial forebrain bundle from E15 onward. Cortical expression can be initially detected prenatally at E21 in rats (Cho et al., 1983). Thus, other CCK sources, as placenta in humans, would be relevant at earlier developmental stages. CCK functional significance in the intrauterine neurogenesis is unknown, however, CCK1 receptors have been associated to adult neurogenesis (Sui et al., 2013). Our transcriptome analysis revealed that VIP and CCK are associated with CHGA (chromogranin A or parathyroid secretory protein 1; Hocker et al., 1998), which encodes for the protein chromogranin A, a prohormone susceptible to be cleavage, generating catestatin, vasostatin and SgII-derived peptides like secretoneurin (Taupenot et al., 2003). These proteins are involved in the biogenesis of secretory granules, neurotransmitter accumulation, and in the control of neurosecretion (Montesinos et al., 2008). Chromogranin A is strongly associated with Alzheimer's disease. It is localized in 
neuritic plaques where it can induce inflammation by activation of the microglia (Yasuhara et al., 1994; Hooper et al., 2009). On the other hand, a reduction in chromogranin A has been found in the layers III-VI of the prefrontal cortex (Brodmann area 9) of schizophrenic subjects, and associated to a lower number of presynaptic terminals and synaptic contacts, accompany by a decreased synaptic transmission (Iwazaki et al., 2004). These antecedents only demonstrate that chromogranin A has a possible functional role in the human brain. Studies about the role of this protein on brain development are needed to draw conclusions about the developmental cortical expression and its association with placental peptides. However, it is remarkable and intriguing that $C H G A$ also is predicted to be interacting with the transcript of beta subunit of chorionic gonadotropin (CG). During pregnancy in some species,including human, CG is secreted by the trophoblast and maintains the progesterone secretion from the corpus luteum at the beginning of gestation. In humans, the production of CG declines around 6-8 weeks of pregnancy. Interestingly, receptors for luteinizing hormone $(\mathrm{LH}) /$ human chorionic gonadotropin (hCG) have been identified in multiple areas of the brain, including the cortex. Also, rat brain expresses these receptors and neurotropic effects of LH and hCG have been demonstrated in fetal rat brain (Lei and Rao, 2001). However, since there are other human placental functionally enriched modules and other species remain to be analyzed, this list can be easily extended in order to obtain a better understanding about the significance of this differential expression. We consider that these preliminary findings are complementary to the better characterized 5-HT signal originated in the placenta and interacting with the fetal forebrain at early developmental stages, the characterization of molecular interactions during development will open new opportunities to interpret evolutionary neurobiology and would reveal the causal relations in the pathogenesis of various cortical developmental disorders (Bonnin et al., 2011). With the exception of PILRA and CECR1, all human predicted transcripts are expressed in the developing cortex of the mouse. Because of this preserved pattern of cortical expression, species-specific interactions seem to be originated in the differentially activated transcripts in human placenta.

\section{CONCLUSION}

The main idea proposed in this article is that the evolutionary expansion of the eutherian brain (specially in primates) would be associated with developmental long distance interactions through molecular signals displayed by the placenta. This hypothesis is

\section{REFERENCES}

Aboitiz, F. (2011). Genetic and developmental homology in amniote brains. Toward conciliating radical views of brain evolution. Brain Res. Bull. 84, 125-136. doi: $\quad 10.1016 /$ j.brainresbull.2010. 12.003

Aboitiz, F., and Montiel, J. (2007). Origin and evolution of the vertebrate telencephalon, with special reference to the mammalian neocortex. Adv. Anat. Embryol. Cell Biol. 193, 1-112.
Aboitiz, F., and Montiel, J. F. (2012). From tetrapods to primates: conserved developmental mechanisms in diverging ecological adaptations. Prog. Brain Res. 195 3-24. doi: 10.1016/B978-0-44453860-4.00001-5

Aboitiz, F., Morales, D., and Montiel, J. (2003). The evolutionary origin of the mammalian isocortex: towards an integrated developmental and functional approach. Behav. Brain Sci. 26, 535-552;

complementary to those relied on the intrinsic control of neocortical development. In addition to the currently described 5-HT developmental interactions between the placenta and the cerebral cortical proliferative compartments, our transcriptomic analysis indicates new candidates for promoting neocortical expansion (e.g., CSPG5, LGALS1, PTK7). Thus, the active interaction between the placenta and the proliferative cortical compartments would amplify the number of neural progenitors as a strategy to increase the total number of neurons in the mature brain. If this proposal is correct, it not only allows to obtain a bigger brain, but also it would permit to reduce the length of the pregnancy required to generate bigger brains, supporting a developmental strategy to escape from fetal-maternal parental conflict. Interestingly, such interactions would conduce to fetal programming changes representing plausible adaptive advantages to environmental demands before and after birth, or maladaptation when there is a mismatch between the programming and the environment requirements (Hsiao and Patterson, 2012). For example, the known effect of maternal undernutrition over offspring metabolism and subsequent susceptibility to obesity later in life (Krechowec et al., 2006; Hsiao and Patterson, 2012). Several maternal insults, including maternal infection and maternal malnutrition, increase susceptibility to intrauterine growth restriction and all these factors are linked to schizophrenia, autism and cerebral palsy in the offspring (Brown and Susser, 2008; Atladóttir et al., 2010; Brown and Patterson, 2011; O'Callaghan etal., 2011). We are aware that detection of placental transcripts expression and their targets alone does not necessarily involves an effective functional interaction, therefore more studies are necessary to establish which mechanisms are implicated at the molecular level. However, according to our preliminary findings, it is remarkable that several pathways would be implicated in placenta-brain interactions and these could have a high impact in order to expand the current understanding of the evolutionary dynamics of neocortical expansion.

\section{ACKNOWLEDGMENTS}

We thank to Gracielle Pereira and Javiera Palma for their critical comments on this manuscript. Heidy Kaune is a recipient of Becas Chile PhD scholarship from the Government of Chile and PhD scholarship for Academics from Universidad Diego Portales, Chile. Juan F. Montiel and Manuel Maliqueo are recipients of Becas Chile postdoctoral fellowship from the Government of Chile.

discussion 552-585. doi: 10.1017/S0140525X03000128

Aono, S., Keino, H., Ono, T., Yasuda, Y., Tokita, Y., Matsui, F., et al. (2000). Genomic organization and expression pattern of mouse neuroglycan $\mathrm{C}$ in the cerebellar development. J. Biol. Chem. 275, 337-342. doi: 10.1074/jbc.275.1.337

Atladóttir, H. O., Thorsen, P., Østergaard, L., Schendel, D. E., Lemcke, S., Abdallah, M., et al. (2010). Maternal infection requiring hospitalization during pregnancy and autism spectrum disorders. J. Autism. Dev. Disord. 40, 1423-1430. doi: 10.1007/s10803-010-1006-y Ayoub, A. E., Oh, S., Xie, Y., Leng, J., Cotney, J., Dominguez, M. H., et al. (2011). Transcriptional programs in transient embryonic zones of the cerebral cortex defined by high-resolution mRNA sequencing. Proc. Natl. Acad. Sci. U.S.A. 108, 14950-14955. doi: 10.1073/pnas. 1112213108 
Barker, D. J., Bull, A. R., Osmond, C., and Simmonds, S. J. (1990). Fetal and placental size and risk of hypertension in adult life. $B M$ ) 301, 259-262. doi: 10.1136/bmj.301. 6746.259

Barros, V. G., Duhalde-Vega, M., Caltana, L., Brusco, A., and Antonelli, M. C. (2006). Astrocyte-neuron vulnerability to prenatal stress in the adult rat brain. J. Neurosci. Res. 83, 787-800. doi: 10.1002/jnr. 20758

Bertrand, N., Castro, D. S., and Guillemot, F. (2002). Proneural genes and the specification of neural cell types. Nat. Rev. Neurosci. 3, 517-530. doi: 10.1038/nrn874

Blackburn, D. G. (1992). Convergent evolution of viviparity, matrotrophy, and specializations for fetal nutrition in reptiles and other vertebrates. Am. Zool. 32, 313-321.

Bonnin, A., Peng, W., Hewlett, W., and Levitt, P. (2006). Expression mapping of 5-HT1 serotonin receptor subtypes during fetal and early postnatal mouse forebrain development. Neuroscience 141, 781-794. doi: $\quad 10.1016 /$ j.neuroscience.2006 04.036

Bonnin, A., Goeden, N., Chen, K., Wilson, M. L., King, J., Shih, J. C., et al. (2011). A transient placental source of serotonin for the fetal forebrain. Nature 472, 347-350. doi: 10.1038/ nature 09972

Brezun, J. M., and Daszuta, A. (1999). Depletion in serotonin decreases neurogenesis in the dentate gyrus and the subventricular zone of adult rats. Neuroscience 89, 999 1002. doi: $10.1016 / \mathrm{S} 0306-4522(98)$ 00693-9

Brown, A. S., and Patterson, P. H. (2011). Maternal infection and schizophrenia: implications for prevention. Schizophr. Bull. 37, 284-290. doi: 10.1093/schbul/ sbq146

Brown, A. S., and Susser, E. S. (2008). Prenatal nutritional deficiency and risk of adult schizophrenia. Schizophr. Bull. 34, 1054-1063. doi: 10.1093/schbul/ sbn096

Brown, R. W., Chapman, K. E., Kotelevtsev, Y., Yau, J. L., Lindsay, R. S., Brett, L., et al. (1996). Cloning and production of antisera to human placental 11 beta-hydroxysteroid dehydrogenase type 2. Biochem. J. 313(Pt 3), 1007-1017.

Caldwell, M. W., and Lee, M. S. (2001). Live birth in Cretaceous marine lizards (mosasauroids). Proc. Biol. Sci. 268, 2397-2401. doi: 10.1098/ rspb.2001.1796
Capellini, I. (2012). The evolutionary significance of placental interdigitation in mammalian reproduction: contributions from comparative studies. Placenta 33, 763-768. doi: $\quad 10.1016 /$ j.placenta.2012. 07.004

Capellini, I., Venditti, C., and Barton, R. A. (2011). Placentation and maternal investment in mammals. Am. Nat. 177, 86-98. doi: 10.1086/ 657435

Carroll, R. L. (1988). Vertebrate Paleontology and Evolution. New York: W. H. Freeman \& Co Press.

Carter, A. M., and Mess, A. (2007). Evolution of the placenta in eutherian mammals. Placenta 28, 259262. doi: 10.1016/j.placenta.2006. 04.010

Castro, D. S., Martynoga, B., Parras, C., Ramesh, V., Pacary, E., Johnston, C., etal. (2011). A novel function of the proneural factor Ascll in progenitor proliferation identified by genome-wide characterization of its targets. Genes Dev 25, 930-945. doi: 10.1101/gad. 627811

Cheung, A. F. P., Kondo, S., AbdelMannan, O., Chodroff, R. A., Sirey, T. M., Bluy, L. E., et al. (2010). The subventricular zone is the developmental milestone of a 6-layered neocortex: comparisons in metatherian and eutherian mammals. Cereb. Cortex 20, 1071-1081. doi: 10.1093/cercor/bhp168

Cheung, A. F. P., Pollen, A. A., Tavare, A., DeProto, J., and Molnár, Z. (2007). Comparative aspects of cortical neurogenesis in vertebrates. J. Anat. 211, 164-176. doi 10.1111/j.1469-7580.2007.00769.x

Cho, H. J., Shiotani, Y., Shiosaka, S., Inagaki, S., Kubota, Y., Kiyama, H., et al. (1983). Ontogeny of cholecystokinin-8-containing neuron system of the rat: an immunohistochemical analysis. I. forebrain and upper brainstem. J. Comp. Neurol. 218, 25-41. doi: $10.1002 /$ cne. 902180103

Clarke, C., Clarke, K., Muneyyirci, J., Azmitia, E., and Whitaker-Azmitia, P. M. (1996). Prenatal cocaine delays astroglial maturation: immunodensitometry shows increased markers of immaturity (vimentin and GAP43) and decreased proliferation and production of the growth factor S100. Brain Res. Dev. Brain Res. 91, 268-273. doi: 10.1016/01653806(95)00192-1

Coe, C. L., Kramer, M., Czéh, B., Gould, E., Reeves, A. J., Kirschbaum, C., et al. (2003). Prenatal stress diminishes neurogenesis in the dentate gyrus of juvenile rhesus monkeys.
Biol. Psychiatry 54, 1025-1034. doi 10.1016/S0006-3223(03)00698-X

Crespi, B., and Semeniuk, C. (2004). Parent-offspring conflict in the evolution of vertebrate reproductive mode. Am. Nat. 163, 635-653. doi: 10.1086/382734

Dehay, C., and Kennedy, H. (2007). Cell-cycle control and cortical development. Nat. Rev. Neurosci. 8, 438450. doi: 10.1038/nrn2097

Dehay, C., Savatier, P., Cortay, V., and Kennedy, H. (2001). Cell-cycle kinetics of neocortical precursors are influenced by embryonic thalamic axons. J. Neurosci. 21, 201-214

Elliot, M. G., and Crespi, B. J. (2008). Placental invasiveness and brain-body allometry in eutherian mammals. J. Evol. Biol. 21, 1763 1778. doi: 10.1111/j.1420-9101.2008. 01590.x

Enders, A., and Blankenship, T. (1999). Comparative placental structure. Adv. Drug Deliv. Rev. 38 3-15. doi: 10.1016/S0169-409X(99) 00003-4

Enders, A. C., and Carter, A. M. (2004). What can comparative studies of placental structure tell us? a review. Placenta 25(Suppl. A), S3-S9. doi: 10.1016/j.placenta.2004. 01.011

Fatemi, S. H., Folsom, T. D., Reutiman, T. J., and Thuras, P. D. (2009). Expression of GABA(B) receptors is altered in brains of subjects with autism. Cerebellum 8, 64-69. doi: 10.1007/s12311-008-0075-3

Fernandez-Twinn, D. S., Ozanne, S. E., Ekizoglou, S., Doherty, C., James, L., Gusterson, B., et al. (2003). The maternal endocrine environment in the low-protein model of intra-uterine growth restriction. Br. J. Nutr. 90, 815-822. doi: 10.1079/BJN2003967

Fietz, S. A., Lachmann, R., Brandl, H., Kircher, M., Samusik, N. Schröder, R., etal. (2012). Transcriptomes of germinal zones of human and mouse fetal neocortex suggest a role of extracellular matrix in progenitor self-renewal. Proc. Natl. Acad. Sci. U.S.A. 109, 11836-11841. doi: 10.1073/pnas. 1209647109

Fowden, A. L., Forhead, A. J., Coan, P. M., and Burton, G. J. (2008). The placenta and intrauterine programming. J. Neuroendocrinol. 20, 439-450. doi 10.1111/j.1365-2826.2008.01663.x

Franceschini, A., Szklarczyk, D., Frankild, S., Kuhn, M., Simonovic, M., Roth, A., et al. (2013). STRING v9.1: protein-protein interaction networks, with increased coverage and integration. Nucleic Acids Res.
41, D808-D815. doi: 10.1093/nar/ gks1094

Franco, S. J., Gil-Sanz, C., MartinezGaray, I., Espinosa, A., HarkinsPerry, S. R., Ramos, C., et al. (2012). Fate-restricted neural progenitors in the mammalian cerebral cortex. Science 337, 746-749. doi: 10.1126/science.1223616

García-Moreno, F., Vasistha, N. A., Trevia, N., Bourne, J. A., and Molnár, Z. (2012). Compartmentalization of cerebral cortical germinal zones in a lissencephalic primate and gyrencephalic rodent. Cereb. Cortex 22, 482-492. doi: 10.1093/cercor/bhr312

Gauthier, J., Kluge, A. G., and Rowe, T. (1988). Amniote phylogeny and the importance of fossils. Cladistics 4, 105-209. doi: 10.1111/j.10960031.1988.tb00514.x

Gustavsson, M., Mallard, C., Vannucci, S. J., Wilson, M. A., Johnston, M. V., and Hagberg, H. (2007). Vascular response to hypoxic preconditioning in the immature brain. J. Cereb. Blood Flow Metab. 27, 928-938.

Hegyi, H. (2013). GABBR1 has a HERV-W LTR in its regulatory region - a possible implication for schizophrenia. Biol. Direct 8, 5. doi: 10.1186/1745-6150-8-5

Hill, J. M. (2007). Vasoactive intestinal peptide in neurodevelopmental disorders: therapeutic potential. Curr. Pharm. Des. 13, 1079-1089. doi: 10.2174/138161207780618975

Hill, J. M., McCune, S. K., Alvero, R. J., Glazner, G. W., Henins, K. A., Stanziale, S. F., etal. (1996). Maternal vasoactive intestinal peptide and the regulation of embryonic growth in the rodent. J. Clin. Invest. 97, 202-208. doi: 10.1172/JCI 118391

Hocker, M., Raychowdhury, R., Plath, T., Wu, H., O'Connor, D. T., Wiedenmann, B., etal. (1998). Spl and CREB mediate gastrin-dependent regulation of chromogranin A promoter activity in gastric carcinoma cells. J. Biol. Chem. 273, 3400034007. doi: 10.1074/jbc.273.51. 34000

Hooper, C., Fry, V. A. H., Sevastou, I. G., and Pocock, J. M. (2009). Scavenger receptor control of chromogranin Ainduced microglial stress and neurotoxic cascades. FEBS Lett. 583, 34613466. doi: 10.1016/j.febslet.2009. 09.049

Hou, Z.-C., Sterner, K. N., Romero, R., Than, N. G., Gonzalez, J. M., Weckle, A., et al. (2012). Elephant transcriptome provides insights into the evolution of eutherian placentation. Genome Biol. Evol. 4, 713-725. doi: 10.1093/gbe/evs045 
Hsiao, E. Y., and Patterson, P. H. (2012). Placental regulation of maternalfetal interactions and brain development. Dev. Neurobiol. 72, 1317-1326. doi: 10.1002/dneu.22045

Imamura, O., Satoh, Y., Endo, S., and Takishima, K. (2008). Analysis of extracellular signal-regulated kinase 2 function in neural stem/progenitor cells via nervous system-specific gene disruption. Stem Cells 26, 3247-3256. doi: 10.1634/stemcells.2008-0578

Iwazaki, T., Shibata, I., Niwa, S., and Matsumoto, I. (2004) Selective reduction of chromogranin A-like immunoreactivities in the prefrontal cortex of schizophrenic subjects: a postmortem study. $\mathrm{Neu}$ rosci. Lett. 367, 293-297. doi: 10.1016/j.neulet.2004.06.034

Jansson, T., and Powell, T. L. (2007). Role of the placenta in fetal programming: underlying mechanisms and potential interventional approaches. Clin. Sci. 113, 1-13. doi: 10.1042/CS20060339

Kaas, J. H. (2013). The evolution of brains from early mammals to humans. Wiley Interdiscip. Rev. Cogn. Sci. 4, 33-45. doi: 10.1002/ wcs. 1206

Karten, H. J. (1969). The organization of the avian telencephalon and some speculations on the phylogeny of the amniote telencephalon. Ann. N. Y. Acad. Sci. 167, 164179. doi: 10.1111/j.1749-6632.1969. tb20442.x

Karten, H. J. (1997). Evolutionary developmental biology meets the brain: the origins of mammalian cortex. Proc. Natl. Acad. Sci. U.S.A 94, 2800-2804. doi: 10.1073/pnas.94. 7.2800

Kemp, T. S. (2006). The origin and early radiation of the therapsid mammal-like reptiles: a palaeobiological hypothesis. J. Evol. Biol. 19, 1231-1247. doi: 10.1111/j.14209101.2005.01076.x

Kielan-Jaworowska, Z., Cifelli, R., and Luo, Z.-X. (2004). Mammals from the Age of Dinosaurs. New York: Columbia University Press.

Krechowec, S. O., Vickers, M., Gertler, A., and Breier, B. H. (2006). Prenatal influences on leptin sensitivity and susceptibility to diet-induced obesity. J. Endocrinol. 189 , 355-363. doi: 10.1677/joe. 1.06679

Kriegstein, A., Noctor, S., and MartínezCerdeño, V. (2006). Patterns of neural stem and progenitor cell division may underlie evolutionary cortical expansion. Nat. Rev. Neurosci. 7, 883-890. doi: 10.1038/ nrn2008
Krubitzer, L. (2007). The magnificent compromise: cortical field evolution in mammals. Neuron 56, 201-208. doi: 10.1016/j.neuron.2007.10.002

Lay, J. M., Gillespie, P. J., and Samuelson, L. C. (1999). Murine prenatal expression of cholecystokinin in neural crest, enteric neurons, and enteroendocrine cells. Dev. Dyn. 216, 190-200. doi: 10.1002/(SICI)10970177(199910)216:2

Le-Niculescu, H., Balaraman, Y., Patel, S. D., Ayalew, M., Gupta, J., Kuczenski, R., et al. (2011). Convergent functional genomics of anxiety disorders: translational identification of genes, biomarkers, pathways and mechanisms. Transl. Psychiatry 1, e9. doi: 10.1038/tp.2011.9

Lei, Z. M., and Rao, C. V. (2001). Neural actions of luteinizing hormone and human chorionic gonadotropin. Semin. Reprod. Med. 19, 103-109. doi: 10.1055/s-200113917

Lewitus, E., and Soligo, C. (2011). Lifehistory correlates of placental structure in eutherian evolution. Evol. Biol. 38, 287-305. doi: 10.1007/s11692011-9115-x

Lidow, M. S., and Rakic, P. (1995). Neurotransmitter receptors in the proliferative zones of the developing primate occipital lobe. J. Comp. Neurol. 360, 393-402. doi: 10.1002/cne. 903600303

Liebner, S., Czupalla, C. J., and Wolburg, H. (2011). Current concepts of blood-brain barrier development. Int. J. Dev. Biol. 55, 467-476. doi: 10.1387/ijdb.103224sl

Luo, Z.-X., Ruf, I., Schultz, J. A., and Martin, T. (2011). Fossil evidence on evolution of inner ear cochlea in Jurassic mammals. Proc. Biol. Sci. 278, 28-34. doi: 10.1098/rspb.2010.1148

Lv, Y. W., Wang, J., Sun, L., Zhang, J. M., Cao, L., Ding, Y. Y., et al (2013). Understanding the pathogenesis of Kawasaki disease by network and pathway analysis. Comput. Math Methods Med. 2013, 989307. doi: $10.1155 / 2013 / 989307$

Martin, R. D. (2003). Human reproduction: a comparative background for medical hypotheses. J. Reprod. Immunol. 59, 111-135. doi: 10.1016/S0165-0378(03)00042-1

Medina, L., and Abellán, A (2009). Development and evolution of the pallium. Semin. Cell Dev. Biol. 20, 698-711. doi: 10.1016/j.semcdb.2009.04.008

Mess, A., and Carter, A. M. (2006) Evolutionary transformations of fetal membrane characters in Eutheria with special reference to Afrotheria.
J. Exp. Zool. B Mol. Dev. Evol. 306, 140-163.

Molnár, Z. (2011). Evolution of cerebral cortical development. Brain Behav. Evol. 78, 94-107. doi: 10.1159/000327325

Molnár, Z., and Clowry, G. (2012). Cerebral cortical development in rodents and primates. Prog. Brain Res. 195, 45-70. doi: 10.1016/B9780-444-53860-4.00003-9

Molnár, Z., Métin, C., Stoykova, A., Tarabykin, V., Price, D. J., Francis, F., et al. (2006). Comparative aspects of cerebral cortical development. Eur. J. Neurosci. 23, 921-934. doi: 10.1111/j.1460-9568.2006.04611.x

Molnár, Z., Vasistha, N. A., and GarcíaMoreno, F. (2011). Hanging by the tail: progenitor populations proliferate. Nat. Neurosci. 14, 538-540. doi: $10.1038 / \mathrm{nn} .2817$

Montesinos, M. S., Machado, J. D. Camacho, M., Diaz, J., Morales, Y. G., Alvarez de la Rosa, D., etal. (2008). The crucial role of chromogranins in storage and exocytosis revealed using chromaffin cells from chromogranin A null mouse. J. Neurosci. 28, 3350-3358. doi: 10.1523/JNEUROSCI.5292-07.2008

Montiel, J. F., Wang, W. Z., Oeschger F. M., Hoerder-Suabedissen, A., Tung, W. L., García-Moreno, F., etal. (2011). Hypothesis on the dual origin of the mammalian subplate. Front. Neuroanat. 5:25. doi: 10.3389/fnana.2011.00025

Mueller, B. R., and Bale, T. L. (2008). Sex-specific programming of offspring emotionality after stress early in pregnancy. J. Neurosci. 28, 9055-9065. doi: 10.1523/JNEUROSCI.1424-08.2008

Munji, R. N., Choe, Y., Li, G., Siegenthaler, J. A., and Pleasure, S. J. (2011). Wnt signaling regulates neuronal differentiation of cortical intermediate progenitors. J. Neurosci. 31, 1676-1687. doi 10.1523/JNEUROSCI.5404-10.2011

Murphy, W. J., Eizirik, E., Johnson, W. E., Zhang, Y. P., Ryder, O. A., and O'Brien, S. J. (2001). Molecular phylogenetics and the origins of placental mammals. Nature 409, 614-618. doi: 10.1038/35054550

Murphy, W. J., Pringle, T. H., Crider T. A., Springer, M. S., and Miller W. (2007). Using genomic data to unravel the root of the placental mammal phylogeny. Genome Res. 17, 413-421. doi: 10.1101/gr.5918807

Nicol, M. B., Hirst, J. J., and Walker, D. (1999). Effects of pregnenolone on behavioral parameters and the responses to $\mathrm{GABA}(\mathrm{A})$ receptor antagonists in the late gestation fetal sheep. Neuropharmacology 38, 49-63. doi: 10.1016/S0028-3908(98) 00166-X

Niimura, Y. (2009). On the origin and evolution of vertebrate olfactory receptor genes: comparative genome analysis among 23 chordate species. Genome Biol. Evol. 1, 34-44. doi: 10.1093/gbe/evp003

O'Callaghan, M. E., MacLennan, A. H., Gibson, C. S., McMichael, G. L., Haan, E. A., Broadbent, J. L., et al. (2011). Epidemiologic associations with cerebral palsy. Obstet. Gynecol. 118, 576-582. doi: 10.1097/AOG.0b013e31822ad2dc

Oftedal, O. T. (2002). The mammary gland and its origin during synapsid evolution. J. Mammary Gland Biol. Neoplasia 7, 225-252. doi: 10.1023/A:1022896515287

O’Leary, M. A., Bloch, J. I., Flynn, J. J., Gaudin, T. J., Giallombardo, A., Giannini, N. P., et al. (2013). The placental mammal ancestor and the post-K-Pg radiation of placentals. Science 339, 662-667. doi: 10.1126/science. 1229237

O'Leary, D. D., and Sahara, S. (2008). Genetic regulation of arealization of the neocortex. Curr. Opin. Neurobiol. 18, 90-100. doi: 10.1016/j.conb.2008.05.011

Peradziryi, H., Kaplan, N. A., Podleschny, M., Liu, X., Wehner, P., Borchers, A., et al. (2011). PTK7/Otk interacts with Wnts and inhibits canonical Wnt signalling. EMBO J. 30, 3729-3740. doi: 10.1038/emboj.2011.236

Peters, H. C., Kämmer, G., Volz, A., Kaupmann, K., Ziegler, A., Bettler, B., et al. (1998). Mapping, genomic structure, and polymorphisms of the human GABABR1 receptor gene: evaluation of its involvement in idiopathic generalized epilepsy. Neurogenetics 2, 47-54. doi: 10.1007/s 100480 050051

Petraglia, F., Florio, P., Nappi, C., and Genazzani, A. R. (1996). Peptide signaling in human placenta and membranes: autocrine, paracrine, and endocrine mechanisms. Endocr. Rev. 17, 156-186.

Petraglia, F., Imperatore, A., and Challis, J. R. G. (2010). Neuroendocrine mechanisms in pregnancy and parturition. Endocr. Rev. 31, 783-816. doi: 10.1210/er.2009-0019

Pontious, A., Kowalczyk, T., Englund, C., and Hevner, R. F. (2008) Role of intermediate progenitor cells in cerebral cortex development. Dev. Neurosci. 30, 24-32. doi: 10.1159/000109848

Prasad, A. B., Allard, M. W., NISC Comparative Sequencing Program, 
and Green, E. D. (2008). Confirming the phylogeny of mammals by use of large comparative sequence data sets. Mol. Biol. Evol. 25, 1795-1808. doi: 10.1093/molbev/ msn104

Quiroga, J. C. (1980). The brain of the mammal-like reptile Probainognathus jenseni (Therapsida, Cynodontia). A correlative paleoneoneurological approach to the neocortex at the reptile-mammal transition. J. Hirnforsch. 21, 299-336.

Reillo, I., de Juan Romero, C., GarciaCabezas, M. A., and Borrell, V. (2011). A role for intermediate radial glia in the tangential expansion of the mammalian cerebral cortex. Cereb. Cortex 21, 1674-1694. doi: 10.1093/cercor/bhq238

Renfree, M. B., Suzuki, S., and KanekoIshino, T. (2013). The origin and evolution of genomic imprinting and viviparity in mammals. Philos. Trans. R. Soc. Lond. B. Biol. Sci. 368, 20120151. doi: 10.1098/rstb. 2012.0151

Reul, J. M., and de Kloet, E. R. (1985). Two receptor systems for corticosterone in rat brain: microdistribution and differential occupation. Endocrinology 117, 2505-2511. doi: 10.1210/endo-117 $-6-2505$

Rowe, T. (1996). Coevolution of the mammalian middle ear and neocortex. Science 273, 651-654. doi: 10.1126/science.273.5275.65

Rowe, T. B., Macrini, T. E., and Luo, Z. X. (2011). Fossil evidence on origin of the mammalian brain. Science 332, 955-957. doi: 10.1126/science. 1203117

Sacher, G. A., and Staffeldt, E. F. (1974). Relation of gestation time to brain weight for placental mammals: implications for the theory of vertebrate growth. Am. Nat. 593-615. doi: $10.1086 / 282938$

Sakaguchi, M., Shingo, T., Shimazaki, T., Okano, H. J., Shiwa, M., Ishibashi, S., et al. (2006). A carbohydratebinding protein, galectin-1, promotes proliferation of adult neural stem cells. Proc. Natl. Acad. Sci. U.S.A. 103, 7112-7117. doi: 10.1073/pnas. 0508793103

Shimogori, T., Banuchi, V., Ng, H. Y., Strauss, J. B., and Grove, E. A.
(2004). Embryonic signaling centers expressing BMP, WNT and FGF proteins interact to pattern the cerebral cortex. Development 131, 5639-5647. doi: 10.1242/dev.01428

Smart, I. H. M., Dehay, C., Giroud, P., Berland, M., and Kennedy, H. (2002). Unique morphological features of the proliferative zones and postmitotic compartments of the neural epithelium giving rise to striate and extrastriate cortex in the monkey. Cereb. Cortex 12, 37-53. doi: 10.1093/cercor/12.1.37

Sui, Y., Vermeulen, R., Hökfelt, T. Horne, M. K., and Stanić, D. (2013). Female mice lacking cholecystokinin 1 receptors have compromised neurogenesis, and fewer dopaminergic cells in the olfactory bulb. Front. Cell Neurosci. 7:13. doi: $10.3389 /$ fncel. 2013.00013

Sur, M., and Rubenstein, J. L. R. (2005). Patterning and plasticity of the cerebral cortex. Science 310, 805-810. doi: 10.1126/science. 1112070

Szklarczyk, D., Franceschini, A., Kuhn, M., Simonovic, M., Roth, A. Minguez, P., etal. (2011). The STRING database in 2011: functional interaction networks of proteins, globally integrated and scored. Nucleic Acids Res. 39, D561-D568. doi: 10.1093/nar/gkq973

Taupenot, L., Harper, K. L., and O'Connor, D. T. (2003). The chromogranin-secretogranin family. N. Engl. J. Med. 348, 1134-1149. doi: 10.1056/NEJMra021405

Ugrumov, M. V. (2010). Developing brain as an endocrine organ: a paradoxical reality. Neurochem. Res. 35 837-850. doi: 10.1007/s11064-0100127-1

Ulupinar, E., and Yucel, F. (2005) Prenatal stress reduces interneuronal connectivity in the rat cerebellar granular layer. Neurotoxicol. Teratol. 27, 475-484. doi: 10.1016/j.ntt. 2005.01.015

Uno, H., Eisele, S., Sakai, A., Shelton, S., Baker, E., DeJesus, O. et al. (1994). Neurotoxicity of glucocorticoids in the primate brain. Horm. Behav. 28, 336-348. doi: 10.1006/hbeh.1994.1030

Uno, H., Lohmiller, L., Thieme, C. Kemnitz, J. W., Engle, M. J., Roecker E. B., etal. (1990). Brain damage induced by prenatal exposure to dexamethasone in fetal rhesus macaques. I. Hippocampus. Brain Res. Dev. Brain Res. 53, 157-167. doi: 10.1016/0165-3806(90)90002-G

Uno, H., Tarara, R., Else, J. G., Suleman, M. A., and Sapolsky, R. M (1989). Hippocampal damage associated with prolonged and fatal stress in primates. J. Neurosci. 9, 1705-1711.

Van den Hove, D. L. A., Lauder, J. M., Scheepens, A., Prickaerts, J., Blanco, C. E., and Steinbusch, H. W. M. (2006). Prenatal stress in the rat alters 5-HT1A receptor binding in the ventral hippocam pus. Brain Res. 1090, 29-34. doi: 10.1016/j.brainres.2006.03.057

Vitalis, T., and Parnavelas, J. G. (2003). The role of serotonin in early cortical development. Dev. Neurosci. 25, 245-256. doi: 10.1159/000072272

Vogel, P. (2005). The current molecular phylogeny of Eutherian mammals challenges previous interpretations of placental evolution. Placenta 26, 591-596. doi: 10.1016/j.placenta.2004.11.005

Waddell, B. J., Wharfe, M. D., Crew, R. C., and Mark, P. J. (2012). A rhythmic placenta? Circadian variation, clock genes and placental function. Placenta 33, 533-539. doi: 10.1016/j.placenta.2012.03.008

Wang, W. Z., Hoerder-Suabedissen, A., Oeschger, F. M., Bayatti, N., Ip, B. K., Lindsay, S., et al. (2010). Subplate in the developing cortex of mouse and human. J. Anat. 217, 368380. doi: $10.1111 /$ j.1469-7580.2010. 01274.x

Wang, W. Z., Oeschger, F. M., Montiel, J. F., García-Moreno, F., HoerderSuabedissen, A., Krubitzer, L., et al. (2011a). Comparative aspects of subplate zone studied with gene expression in sauropsids and mammals. Cereb. Cortex 21, 2187-2203. doi: $10.1093 /$ cercor/bhq278

Wang, X., Tsai, J.-W., LaMonica, B. and Kriegstein, A. R. (2011b). A new subtype of progenitor cell in the mouse embryonic neocortex. Nat. Neurosci. 14, 555-561. doi: 10.1038/ nn. 2807

Weisbecker, V., and Goswami, A. (2010). Brain size, life history, and metabolism at the marsupial/placental dichotomy. Proc. Natl. Acad. Sci. U.S.A. 107, 16216-16221. doi: 10.1073/pnas.0906486107
Wildman, D. E., Chen, C., Erez, O., Grossman, L. I., Goodman, M., and Romero, R. (2006). Evolution of the mammalian placenta revealed by phylogenetic analysis. Proc. Natl. Acad. Sci. U.S.A. 103, 3203-3208. doi: 10.1073/pnas. 0511344103

Yasuhara, O., Kawamata, T., Aimi, Y., McGeer, E. G., and McGeer, P. L. (1994). Expression of chromogranin $\mathrm{A}$ in lesions in the central nervous system from patients with neurological diseases. Neurosci. Lett. 170, 13-16. doi: 10.1016/0304-3940(94) 90227-5

Yawno, T., Hirst, J. J., CastilloMelendez, M., and Walker, D. W. (2009). Role of neurosteroids in regulating cell death and proliferation in the late gestation fetal brain. Neuroscience 163, 838-847. doi: $\quad 10.1016 /$ j.neuroscience.2009. 07.009

Yawno, T., Yan, E. B., Walker, D. W., and Hirst, J. J. (2007). Inhibition of neurosteroid synthesis increases asphyxia-induced brain injury in the late gestation fetal sheep. Neuroscience 146, 1726-1733. doi: $\quad 10.1016 /$ j.neuroscience.2007. 03.023

Conflict of Interest Statement: The authors declare that the research was conducted in the absence of any commercial or financial relationships that could be construed as a potential conflict of interest.

Received: 31 March 2013; paper pending published: 22 April 2013; accepted: 25 June 2013; published online: 19 July 2013.

Citation: Montiel JF, Kaune $H$ and Maliqueo M (2013) Maternal-fetal unit interactions and eutherian neocortical development and evolution. Front. Neuroanat. 7:22. doi: 10.3389/fnana.2013. 00022

Copyright (c) 2013 Montiel, Kaune and Maliqueo. This is an open-access article distributed under the terms of the Creative Commons Attribution License, which permits use, distribution and reproduction in other forums, provided the original authors and source are credited and subject to any copyright notices concerning any third-party graphics etc. 